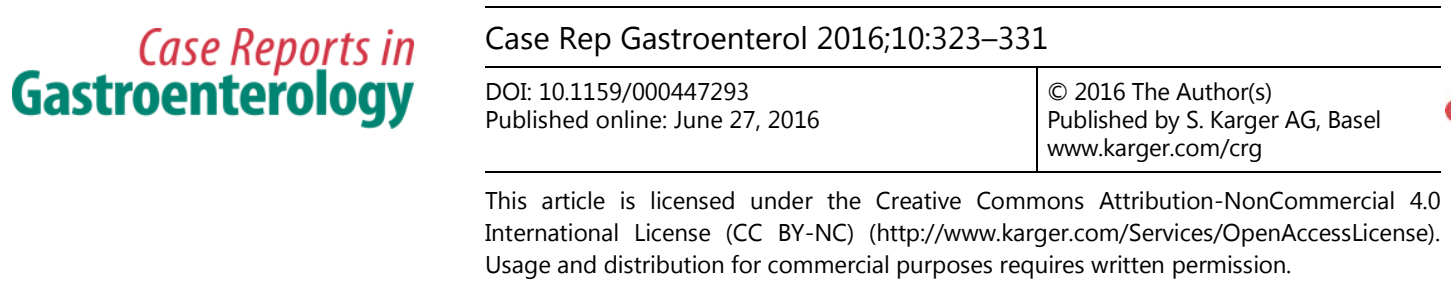

\title{
Early, Isolated Duodenal Mucosa- Associated Lymphoid Tissue Lymphoma Presenting without Symptoms or Grossly Apparent Endoscopic Lesions and Diagnosed by Random Duodenal Biopsies
}

\author{
Mihajlo Gjeorgjievski ${ }^{a} \quad$ Issa Makki $^{a} \quad$ Pradeep Khanal $^{a} \quad$ Mitual B. Amin ${ }^{b}$ \\ Ann Marie Blenc ${ }^{c}$ Tusar Desai ${ }^{d} \quad$ Mitchell S. Cappell $^{e}$ \\ ${ }^{a}$ Division of Gastroenterology and Hepatology, Department of Medicine, William \\ Beaumont Hospital, Royal Oak, Mich., USA; ${ }^{b}$ Department of Pathology, William Beaumont \\ Hospital, Royal Oak, Mich., USA; ${ }^{C}$ Department of Pathology, Oakland University William \\ Beaumont School of Medicine, Royal Oak, Mich., USA; ${ }^{d}$ Division of Gastroenterology and \\ Hepatology, Oakland University William Beaumont Hospital, Royal Oak, Mich., USA; \\ ${ }^{\mathrm{e}}$ Division of Gastroenterology, Oakland University William Beaumont School of Medicine, \\ Royal Oak, Mich., USA
}

\section{Keywords}

Duodenum · Lymphoma - Mucosa-associated lymphoid tissue lymphoma $\cdot$ Helicobacter pylori - Esophagogastroduodenoscopy

\begin{abstract}
Clinical data regarding mucosa-associated lymphoid tissue lymphoma (MALToma) solely involving the duodenum are sparse because of the relative rarity of the disease. A comprehensive literature review revealed only 17 cases reported until 2004, and only a moderate number of cases have been reported since. MALToma can be asymptomatic in its very early stages but frequently produces localized or nonspecific symptoms, including early satiety, abdominal pain, vomiting, and involuntary weight loss in later stages. While gastric
\end{abstract}




\section{Case Reports in Gastroenterology}

Case Rep Gastroenterol 2016;10:323-331 $10.1159 / 000447293$

(C) 2016 The Author(s). Published by S. Karger AG, Basel www.karger.com/crg

Gjeorgjievski et al.: Early, Isolated Duodenal MALToma Presenting without Symptoms or Grossly Apparent Endoscopic Lesions and Diagnosed by Random Duodenal Biopsies

MALToma is strongly associated with gastric Helicobactor pylori infection, duodenal MALToma is often unassociated with $\mathrm{H}$. pylori infection. A 74-year-old female presented with only dysphagia (without symptoms referable to a duodenal lesion), without systemic ' $B$ ' symptoms, and with no evident duodenal lesions at esophagogastroduodenoscopy; however, she was diagnosed with duodenal MALToma by pathologic examination of random duodenal biopsies performed to exclude celiac disease. An important clinical feature of this case is that duodenal MALToma was diagnosed by pathologic analysis of duodenal biopsies despite (1) no endoscopically apparent duodenal lesions; (2) duodenal involvement without gastric involvement; (3) lack of symptoms attributable to duodenal MALToma, and (4) absence of evident $H$. pylori infection. This work shows that early duodenal MALToma can be difficult to diagnose because of absent symptoms, absence of gastric involvement, absence of endoscopic abnormalities, and absence of $\mathrm{H}$. pylori infection; it may require random duodenal biopsies for diagnosis.

(C) 2016 The Author(s)

Published by S. Karger AG, Basel

\section{Introduction}

Mucosa-associated lymphoid tissue lymphoma (MALToma) is the third most common non-Hodgkin's lymphoma, representing about $8 \%$ of all non-Hodgkin's lymphomas $[1,2]$. MALTomas occur predominantly in the stomach [3]. Much data have accumulated about the pathogenesis, clinical presentation, pathology, and treatment of gastric MALTomas because these are relatively common. The normal stomach contains scant lymphoid tissue, but gastric infection with Helicobacter pylori leads to accumulation of CD4+ lymphocytes and B lymphocytes in the gastric lamina propria, followed by B-lymphocyte proliferation and the formation of lymphoid follicles [4]. Continued activation, replication, and proliferation of these lymphocytes can lead to MALToma and transformed lymphocytes [4]. Indeed, gastric MALToma is highly associated with $H$. pylori infection, with up to $90 \%$ of patients with gastric MALToma having serologic markers of $H$. pylori infection [4].

The close association between $H$. pylori infection and MALToma is strikingly demonstrated by complete histologic, long-term remission in $50-80 \%$ of patients with localized, early, gastric MALTomas after $H$. pylori eradication, using combination proton pump inhibitor and antibiotic therapy [5-7]. Patients initially treated with $H$. pylori eradication therapy require a follow-up to confirm $H$. pylori eradication as well as retreatment with another $H$. pylori eradication regimen if the infection was not entirely eradicated [8]. Patients achieving H. pylori eradication should then undergo periodic surveillance esophagogastroduodenoscopy (EGD) until complete histologic response is achieved and thereafter undergo ongoing surveillance EGD to confirm persistence of both complete histologic response and H. pylori eradication [8]. However, advanced MALTomas, associated with chromosomal $t(11 ; 18)$ translocation, are unlikely to remit with anti-H. pylori therapy and thus generally require local radiotherapy, chemotherapy, or surgery [9].

Contrariwise, data regarding the clinical presentation, natural history, pathophysiology, and therapy of duodenal MALTomas are scant because duodenal MALTomas are relatively rare $[10,11]$. Duodenal MALTomas appear to have a different pathophysiology and therapy than gastric MALTomas. For example, duodenal MALTomas are relatively rarely associated with $H$. pylori infection and, therefore, are not usually treated with a combination of antibiotic and proton pump inhibitor therapy to eradicate H. pylori [12]. We present a patient with localized duodenal MALToma who presented without (1) attributable symptoms, (2) endoscopically apparent duodenal lesions, and (3) evident $H$. pylori infection. This work illus- 
trates the clinically important finding that early duodenal MALTomas may present without symptoms and may require random duodenal biopsies for diagnosis; we then reviewed the literature on duodenal MALTomas to contrast the biology and natural history of duodenal MALTomas with that of gastric MALTomas and describe what is known or unknown about duodenal MALTomas.

\section{Methods}

A comprehensive, computerized, literature review was performed using PubMed with the following MeSH (medical subject headings) or key words: 'gastrointestinal MALToma'; 'small bowel MALToma'; 'intestinal MALToma'; 'gastric MALToma', or 'endoscopy' or 'esophagogastroduodenoscopy' and 'MALToma'. This case received approval/exemption by the Institutional Review Board of William Beaumont Hospital at Royal Oak on March 4, 2016.

\section{Case Report}

A 74-year-old woman, with a past medical history of end-stage renal disease, mild chronic obstructive pulmonary disease, left ventricular hypertrophy, mild chronic iron deficiency anemia, chronic gastroesophageal reflux disease treated with proton pump inhibitors, and no known autoimmune disorders presented with dysphagia for solids without abdominal pain or other gastrointestinal (GI) symptoms, and without systemic ' $\mathrm{B}$ ' symptoms of pyrexia, night sweats, or weight loss. She had a 10-pack-year history of smoking cigarettes, but had quit smoking 10 years earlier. She drank alcohol only socially and did not use any illicit drugs. Physical examination revealed a blood pressure of 145/78 $\mathrm{mm} \mathrm{Hg}$, a heart rate of 98 beats $/ \mathrm{min}$, and a temperature of $36.5^{\circ} \mathrm{C}$. The abdominal examination was unremarkable, including findings of a nontender abdomen, normoactive bowel sounds, and no hepatosplenomegaly. Rectal examination revealed no fecal occult blood. Laboratory analysis showed a hemoglobin level of $10.3 \mathrm{~g} / \mathrm{dl}$, a mean corpuscular volume of $87 \mathrm{fl}$, a serum iron level of $25 \mu \mathrm{g} / \mathrm{dl}$, and a total iron binding capacity of $223 \mu \mathrm{g} / \mathrm{dl}$ (iron saturation 11\%, compatible with iron deficiency anemia). The serum levels of sodium were $136 \mathrm{mmol} / \mathrm{l}$, potassium $3.7 \mathrm{mmol} / \mathrm{l}$, chloride $98 \mathrm{mmol} / \mathrm{l}$, and bicarbonate $26 \mathrm{mmol} / \mathrm{l}$. The serum creatinine level was $2.71 \mathrm{mg} / \mathrm{dl}$, and blood urea nitrogen was $27 \mathrm{mg} / \mathrm{dl}$. Serum tests of liver function were all within normal limits, except that the alkaline phosphatase level was $263 \mathrm{U} / \mathrm{l}$. The albumin level was low at $2.7 \mathrm{~g} / \mathrm{dl}$. The lactate dehydrogenase level was $206 \mathrm{U} / \mathrm{l}$ (normal range 100238). A barium esophagogram revealed no abnormalities. EGD revealed no gross duodenal lesions and some digested food obscuring about $20 \%$ of the descending duodenal mucosa despite her having fasted for $8 \mathrm{~h}$ before EGD (fig. 1). There were no gastric or esophageal lesions. Histologic analysis of esophageal biopsies, performed because of dysphagia, revealed no lesions. Histologic analysis of endoscopic biopsies of the descending duodenum, performed to exclude celiac disease in a patient with suspected iron deficiency anemia, revealed a prominent submucosal lymphocytic infiltrate with scattered plasma cells, consistent with low-grade B-cell non-Hodgkin's lymphoma and otherwise normal mucosa (fig. 2a, b). Immunohistochemistry predominantly revealed B cells, with a strong expression of CD43 and a coexpression of BCL2, findings highly compatible with extranodular marginal zone MALToma (fig. 2c, d). Microscopic examination of gastroduodenal biopsies using a modified Giemsa stain (Diff Quick stain; Electron Microscopy Sciences, Hatfield, Pa., USA) was negative 
for H. pylori, as was immunohistochemistry using antibodies to H. pylori. The serum IgG antibody level to $H$. pylori was $0.41 \mathrm{U} / \mathrm{ml}$ (levels of $0.00-0.89 \mathrm{U} / \mathrm{ml}$ compatible with no infection). Serum tissue transglutaminase IgA antibody levels were $7.1 \mathrm{U} / \mathrm{ml}(<20 \mathrm{U} / \mathrm{ml}$ negative for celiac disease), with a normal serum IgA level and no monoclonal gammopathy. An abdominal PET scan revealed small, minimally fludeoxyglucose-avid, mesenteric and periaortic lymph nodes. The patient agreed to undergo treatment for duodenal MALToma in the future.

\section{Discussion}

MALToma is histologically characterized by diffuse infiltration of neoplastic, centrocytelike cells distributed in marginal zones around reactive, secondary, lymphoid follicles in the lamina propria $[2,13]$. GI MALTomas usually occur in the stomach, sometimes the jejunum ileum, and rarely the duodenum. For example, in a study of 307 cases of primary GI nonHodgkin's lymphoma, 244 cases (80\%) had gastric lymphoma and 63 cases (20\%) intestinal lymphoma [14], whereas in another study of $150 \mathrm{GI}$ lymphomas, 105 patients had gastric lymphoma, 27 patients had jejunoileal lymphoma, and only 1 patient had primary duodenal lymphoma [15]. The literature review of duodenal MALTomas identified only 17 cases reported before 2004 [16], and only moderately more cases have been reported since [11, 1734].

Gastric MALTomas commonly present with GI symptoms of epigastric pain, nausea and vomiting, and gross upper GI bleeding, or with constitutional symptoms of loss of appetite, involuntary weight loss, and night sweats [35]. Symptoms from duodenal lymphomas depend upon lesion location, size, and degree of luminal obstruction [36]. Common clinical presentations include abdominal pain, GI bleeding, and anemia. Najem et al. [37] divided duodenal lymphomas into the following 4 groups based on growth characteristics and symptomatology: (1) obstructive lesions associated with early satiety, vomiting, and postprandial pain; (2) ulcerating lesions associated with GI bleeding, manifesting as hematemesis, melena, or anemia; (3) penetrating lesions associated with typical symptoms of peptic ulcers, and (4) periampullary lesions associated with jaundice. Weight loss may occur in any group. Acute pancreatitis or gastric outlet obstruction are rare presentations [11,38]. However, duodenal MALTomas are occasionally asymptomatic, or present with nonspecific abdominal pain, especially when diagnosed as early and small lesions [11].

In a review of 38 publications incorporating 2,000 patients with gastric MALTomas, patients almost always presented with endoscopic abnormalities, including gastric erosions, nodularity, enlarged folds, ulceration, polyps, mass, petechiae, or hyperemic mucosa; gastric MALToma without endoscopic abnormalities was rare [39, 40]. Duodenal MALTomas appear similarly at EGD [41]. A comprehensive literature review revealed that duodenal MALTomas rarely present with no endoscopically apparent lesions [16-18, 20-23, 25-27, 30, 31, 34, 42-48].

The current case report illustrates that duodenal MALTomas may be unassociated with H. pylori infection. H. pylori is strongly associated with gastric MALTomas and is believed to play a role in the pathogenesis of MALTomas by stimulating lymphocyte activation, proliferation, and transformation from chronic inflammation induced by $H$. pylori infection, but its role in duodenal MALTomas is unclear. Duodenal MALTomas are typically independent of $H$. pylori infection [40] and generally persist despite treatment and eradication of $H$. pylori [16]. However, duodenal MALTomas may occasionally regress after $H$. pylori eradication [41]. 
Due to its rarity, no consensus exists regarding duodenal MALToma therapy [29]. Surgery is often recommended to eradicate and achieve a nearly $100 \%$ cure for localized duodenal lymphoma/MALToma, as demonstrated in a study which included 15 patients with duodenal lymphomas/MALTomas [49]. Some authorities argue that surgery may be too aggressive and advocate for chemotherapy [29]. In a study of 4 patients treated with cyclophosphamide $100 \mathrm{mg} /$ day for 18 months without surgery, 2 patients had complete remission for 2 years and 1 patient had complete remission for 65 months [50]. Rituximab has been used for gastric (but not duodenal) MALToma: 20 of 26 patients with gastric nonHodgkin's lymphoma achieved an objective response with rituximab [51]. In the currently reported case, MALToma therapy was postponed, in accord with the patient's preferences, because the lesion was asymptomatic, localized, and detected very early.

In this case report, the presenting symptom of dysphagia that prompted EGD is not attributable to the duodenal MALToma. The major finding of the current work is that very early duodenal MALTomas can present with no symptoms, produce no grossly evident duodenal lesions at EGD, and may require biopsies of normal appearing duodenal tissue for diagnosis. The lack of mucosal lesions at EGD with early disease may reflect the predominant involvement of the lamina propria or deeper tissue without superficial mucosal involvement.

Study limitations primarily include that this report is retrospective and involves only 1 case. Secondly, the entire descending duodenum was not visualized at EGD because of residual partly digested food, and, therefore, a small duodenal lesion hidden behind partly digested food could not be entirely excluded. However, the great majority of the descending duodenum was visualized at EGD, and pathologic examination of an endoscopic biopsy from normal appearing duodenal mucosa revealed MALToma. Thirdly, we cannot completely exclude that the reported iron deficiency anemia arose from GI bleeding from the MALToma. However, the patient had no fecal occult blood and no (ulcerating) lesions detected at EGD. Furthermore, it is unlikely that the iron deficiency anemia resulted from malabsorption of ingested iron because the patient had early duodenal MALToma, as indicated by no evident endoscopic lesions, as well as indolent MALToma, as indicated by the absence of all of the following 5 aggressive factors: evident disseminated disease [52], peripheral blood involvement [53], presence of 'B' symptoms, an elevated lactate dehydrogenase [54], and a monoclonal gammopathy [55]. Fourthly, the clinical impact of the current report of clinically occult duodenal MALToma is limited by a lack of consensus regarding therapy for asymptomatic, early duodenal MALToma.

\section{Statement of Ethics}

The authors report no ethical problem.

\section{Disclosure Statement}

The authors report no conflicts of interest. This paper does not discuss any confidential pharmaceutical industry data reviewed by Dr. Cappell as a consultant for the United States Food and Drug Administration (FDA) Advisory Committee on Gastrointestinal Drugs. Dr. Cappell is a speaker for Movantik, a drug jointly manufactured by AstraZeneca and Daiichi Sankyo. This work does not discuss any drug or medical device manufactured or marketed by AstraZeneca or Daiichi Sankyo. 


\section{Case Reports in \\ Gastroenterology}

\begin{tabular}{l|l}
\hline Case Rep Gastroenterol 2016;10:323-331 \\
\hline $10.1159 / 000447293$ & (c 2016 The Author(s). Published by S. Karger AG, Basel
\end{tabular} www.karger.com/crg

Gjeorgjievski et al.: Early, Isolated Duodenal MALToma Presenting without Symptoms or Grossly Apparent Endoscopic Lesions and Diagnosed by Random Duodenal Biopsies

\section{References}

-1 A clinical evaluation of the International Lymphoma Study Group classification of non-Hodgkin's lymphoma. The Non-Hodgkin's Lymphoma Classification Project. Blood 1997;89:3909-3918.

-2 Bacon CM, Du MQ, Dogan A: Mucosa-associated lymphoid tissue (MALT) lymphoma: a practical guide for pathologists. J Clin Pathol 2007;60:361-372.

-3 Xu X, Wang Z, Yu Y, Wang Y, Zhang L, Sun B, Da W, Zhang Y: Evaluation of the clinical characteristics and prognostic factors of gastrointestinal mucosa-associated lymphoid tissue (MALT) lymphoma. ] Gastroenterol Hepatol 2014;29:1678-1684.

-4 Zucca E, Bertoni F, Roggero E, Bosshard G, Cazzaniga G, Pedrinis E, Biondi A, Cavalli F: Molecular analysis of the progression from Helicobacter pylori-associated chronic gastritis to mucosa-associated lymphoid-tissue lymphoma of the stomach. N Engl J Med 1998;338:804-810.

5 Nakamura S, Matsumoto T: Helicobacter pylori and gastric mucosa-associated lymphoid tissue lymphoma: recent progress in pathogenesis and management. World J Gastroenterol 2013;19:81818187.

6 Gisbert JP, Calvet X: Review article: common misconceptions in the management of Helicobacter pyloriassociated gastric MALT-lymphoma. Aliment Pharmacol Ther 2011;34:1047-1062.

-7 Zullo A, Hassan C, Andriani A, Cristofari F, De Francesco V, Ierardi E, Tomao S, Morini S, Vaira D: Eradication therapy for Helicobacter pylori in patients with gastric MALT lymphoma: a pooled data analysis. Am J Gastroenterol 2009;104:1932-1937.

-8 ESMO Guidelines Working Group, Zucca E: Gastric marginal zone lymphoma of mucosa-associated lymphoid tissue type: ESMO clinical recommendations for diagnosis, treatment and follow-up. Ann Oncol 2007;18(suppl 2):ii59-ii60.

-9 Montalban C, Norman F: Treatment of gastric mucosa-associated lymphoid tissue lymphoma: Helicobacter pylori eradication and beyond. Expert Rev Anticancer Ther 2006;6:361-371.

$\checkmark 10$ Wang HH, Lin JT, Chiu CC, Chiang IP, Wu MS, Wang TH: Endoscopic features of mucosa-associated lymphoid tissue lymphoma of the duodenum. Gastrointest Endosc 1995;41:258-261.

-11 Saluja SS, Kalayarasan R, Mishra PK, Saran RK: Duodenal MALToma with gastric outlet obstruction. Case report and review of literature. J Gastrointest Cancer 2012;43:329-331.

12 Zucca E, Bertoni F: The spectrum of MALT lymphoma at different sites: biological and therapeutic relevance. Blood 2016;127:2082-2092.

-13 Cohen SM, Petryk M, Varma M, Kozuch PS, Ames ED, Grossbard ML: Non-Hodgkin's lymphoma of mucosa-associated lymphoid tissue. Oncologist 2006;11:1100-1117.

14 Radaszkiewicz T, Dragosics B, Bauer P: Gastrointestinal malignant lymphomas of the mucosaassociated lymphoid tissue: factors relevant to prognosis. Gastroenterology 1992;102:1628-1638. Dragosics B, Bauer P, Radaszkiewicz T: Primary gastrointestinal non-Hodgkin's lymphomas. A retrospective clinicopathologic study of 150 cases. Cancer 1985;55:1060-1073.

-16 Xiang Z, Onoda N, Ohira M, et al: Mucosa-associated lymphoid tissue lymphoma of the duodenum: report of a case resistant to Helicobacter pylori eradication. Hepatogastroenterology 2004;51:732-735.

$\checkmark 17$ Al-Amri A, Al-Quorain AA: Coexisting malignant lymphoma of the duodenum and adenocarcinoma of the colon. Saudi Med J 2007;28:463-464.

18 Azar C, Soweid A, Berro Z, et al: Duodenal mucosa-associated lymphoid tissue lymphoma successfully treated by radiation therapy. Clin Lymphoma Myeloma 2007;7:428-431.

-19 Carman R, Snyder J, Davidson M: Primary mucosa-associated lymphoid tumor lymphoma of the duodenum: a rare presentation of non-Hodgkin's lymphoma. J Clin Oncol 2011;29:e226-e229.

20 Chestovich PJ, Schiller G, Sasu S, Hiatt JR: Duodenal lymphoma: a rare and morbid tumor. Am Surg 2007;73:1057-1062.

21 Cho SJ, Ryu KW, Kim CG, et al: Duodenal mucosa-associated lymphoid tissue lymphoma masquerading as an ulcer scar. Endoscopy 2008;40(suppl 2):E175.

$\checkmark 22$ Iwamuro M, Okada H, Takata K, et al: Diagnostic accuracy of endoscopic biopsies for the diagnosis of gastrointestinal follicular lymphoma: a clinicopathologic study of 48 patients. Ann Diagn Pathol 2014;18:99-103.

23 Kim SJ, Kim HW, Choi CW, et al: Duodenal mucosa-associated lymphoid tissue lymphomas: two cases and the evaluation of endoscopic ultrasonography. Clin Endosc 2013;46:563-567.

-24 Merino LA, Arranz EM, Sanz PM, et al: Duodenal MALT lymphoma; infrequent location. Rev Esp Enferm Dig 2010;102:672.

25 Nahm DI, Baek IH, Lee MS: Primary duodenal MALT lymphoma. Korean J Gastroenterol 2007;49:343345.

26 Patel VG, Eltayeb OM, Henderson VJ, et al: Primary duodenal low-grade mucosa-associated lymphoid tissue lymphoma presenting with outlet obstruction. Am Surg 2004;70:613-616.

27 Sato Y, Ichimura K, Tanaka T, et al: Duodenal follicular lymphomas share common characteristics with mucosa-associated lymphoid tissue lymphomas. J Clin Pathol 2008;61:377-381. 


\section{Case Reports in \\ Gastroenterology}

Case Rep Gastroenterol 2016;10:323-331

(c) 2016 The Author(s). Published by S. Karger AG, Basel www.karger.com/crg

Gjeorgjievski et al: Early, Isolated Duodenal MALToma Presenting without Symptoms or Grossly Apparent Endoscopic Lesions and Diagnosed by Random Duodenal Biopsies

Shirsat HS, Vaiphei K: Primary gastrointestinal lymphomas - a study of 81 cases from a tertiary healthcare centre. Indian J Cancer 2014;51:290-292.

Tadmor T, Rainis T, Bejar J, Attias D, Lavy A: Primary duodenal mucosa-associated lymphoid tissue (MALT) lymphoma - a rare presentation of gastric outlet obstruction. Can J Gastroenterol 2007;21:393-395.

Usmani SZ, Ding L, Abu-rashed AH, Saleh HA: Duodenal MALT lymphoma presenting with obstructive jaundice: report of a case and review of the literature. J Gastrointest Cancer 2007;38:28-31.

Ventrucci M, Gherlinzoni F, Sabattini E, Cipolla A, Ubalducci GM, Pileri S: Primary MALT-lymphoma of the papilla of Vater. Dig Dis Sci 1998;43:214-216.

Woo KH, Kim JH, Yoon SB, et al: Duodenal mucosa-associated lymphoid tissue lymphoma: a case report. Korean J Intern Med 2007;22:296-299.

Yamashita H, Nakagawa K, Asari T, Murakami N, Igaki H, Ohtomo K: Radiotherapy for 41 patients with stages I and II MALT lymphoma: a retrospective study. Radiother Oncol 2008;87:412-417.

Zippi M, Pica R, Scialpi R, Paoluzi P, Occhigrossi G: Simultaneous primary gastric and duodenal MALT lymphoma presenting with gastrointestinal bleeding. Clin Ter 2012;163:e165-e167.

Koch P, del Valle F, Berdel WE, Willich NA, Reers B, Hiddemann W, Grothaus-Pinke B, Reinartz G, Brockmann J, Temmesfeld A, Schmitz R, Rübe C, Probst A, Jaenke G, Bodenstein H, Junker A, Pott C, Schultze J, Heinecke A, Parwaresch R, Tiemann M; German Multicenter Study Group: Primary gastrointestinal non-Hodgkin's lymphoma. 1. Anatomic and histologic distribution, clinical features, and survival data of 371 patients registered in the German Multicenter Study GIT NHL 01/92. J Clin Oncol 2001;19:3861-3873.

Copeland MM, Greiner DJ: Lymphosarcoma of the duodenum; report of a case; review of the literature. Arch Surg 1949;58:511-528.

Najem AZ, Porcaro JL, Rush BF: Primary non-Hodgkin's lymphoma of the duodenum. Case report and literature review. Cancer 1984;54:895-898.

Simkova I, Urbanek K, Prochazka V, et al: Acute pancreatitis as the first manifestation of duodenal MALT lymphoma. Biomed Pap Med Fac Univ Palacky Olomouc Czech Repub 2015;159:688-694. Zullo A, Hassan C, Andriani A, et al: Primary low-grade and high-grade gastric MALT-lymphoma presentation. J Clin Gastroenterol 2010;44:340-344.

Vetro C, Romano A, Amico I, et al: Endoscopic features of gastro-intestinal lymphomas: from diagnosis to follow-up. World J Gastroenterol 2014;20:12993-13005.

Nagashima R, Takeda H, Maeda K, Ohno S, Takahashi T: Regression of duodenal mucosa-associated lymphoid tissue lymphoma after eradication of Helicobacter pylori. Gastroenterology 1996;111:16741678.

Ieko M, Kohno M, Ohmoto A, et al: Gamma-heavy chain disease associated with MALT lymphoma of the duodenum. Rinsho Ketsueki 1998;39:512-518.

Kim JS, Jung HC, Shin KH, Song IS, Kim CW, Kim CY: Eradication of Helicobacter pylori infection did not lead to cure of duodenal mucosa-associated lymphoid tissue lymphoma. Scand J Gastroenterol 1999;34:215-218.

Nakamura S, Matsumoto T, Nakamura S, et al: Duodenal mucosa-associated lymphoid tissue lymphoma treated by eradication of Helicobacter pylori: report of 2 cases including EUS findings. Gastrointest Endosc 2001;54:772-775.

Leone N, Brunello F, Baronio M, et al: High-grade B-cell lymphoma arising in mucosa-associated lymphoid tissue of the duodenum. Eur J Gastroenterol Hepatol 2002;14:893-896.

Ohtsuka T, Kodama K, Nishikata F, Okada K, Nakano R, Iwata Y: Mucosa-associated lymphoid tissue lymphoma of the duodenum forming multiple polypoid lesions: report of a case. Surg Today 1999;29:557-559.

Tari A, Asaoku H, Tani H, et al: Evaluation of non-surgical therapy for the malignant lymphomas located mainly in the stomach and duodenum. Nihon Shokakibyo Gakkai Zasshi 2001;98:1154-1163. Toshima M, Aikawa K, Soga K, Shibasaki K, Yoshida K, Emura I: Primary duodenal MALT lymphoma. Intern Med 1999;38:957-961.

Ruskoné-fourmestraux A, Aegerter P, Delmer A, Brousse N, Galian A, Rambaud JC: Primary digestive tract lymphoma: a prospective multicentric study of 91 patients. Groupe d'Etude des Lymphomes Digestifs. Gastroenterology 1993;105:1662-1671.

Lepicard A, Lamarque D, Lévy M, et al: Duodenal mucosa-associated lymphoid tissue lymphoma: treatment with oral cyclophosphamide. Am J Gastroenterol 2000;95:536-539.

Martinelli G, Laszlo D, Ferreri AJ, et al: Clinical activity of rituximab in gastric marginal zone nonHodgkin's lymphoma resistant to or not eligible for anti-Helicobacter pylori therapy. J Clin Oncol 2005;23:1979-1983.

Thieblemont C, Berger F, Dumontet C, Moullet I, Bouafia F, Felman P, Salles G, Coiffier B: Mucosaassociated lymphoid tissue lymphoma is a disseminated disease in one third of 158 patients analyzed. Blood 2000;95:802. 


\title{
Case Reports in \\ Gastroenterology
}

\begin{tabular}{l|l}
\hline Case Rep Gastroenterol 2016;10:323-331 \\
\hline $10.1159 / 000447293$ & $\begin{array}{l}\text { C 2016 The Author(s). Published by S. Karger AG, Basel } \\
\text { www.karger.com/crg }\end{array}$ \\
\hline
\end{tabular}

Gjeorgjievski et al: Early, Isolated Duodenal MALToma Presenting without Symptoms or Grossly Apparent Endoscopic Lesions and Diagnosed by Random Duodenal Biopsies

\begin{abstract}
53 Carbone A, Gloghini A, Pinto A, Attadia V, Zagonel V, Volpe R: Monocytoid B-cell lymphoma with bone marrow and peripheral blood involvement at presentation. Am J Clin Pathol 1989;92:228.

54 Arcaini L, Paulli M, Burcheri S, Rossi A, Spina M, Passamonti F, Lucioni M, Motta T, Canzonieri V, Montanari M, Bonoldi E, Gallamini A, Uziel L, Crugnola M, Ramponi A, Montanari F, Pascutto C, Morra E, Lazzarino M; Intergruppo Italiano Linfomi: Primary nodal marginal zone B-cell lymphoma: clinical features and prognostic assessment of a rare disease. Br J Haematol 2007;136:301.

-55 Asatiani E, Cohen P, Ozdemirli M, Kessler CM, Mavromatis B, Cheson BD: Monoclonal gammopathy in extranodal marginal zone lymphoma (ENMZL) correlates with advanced disease and bone marrow involvement. Am J Hematol 2004;77:144.
\end{abstract}

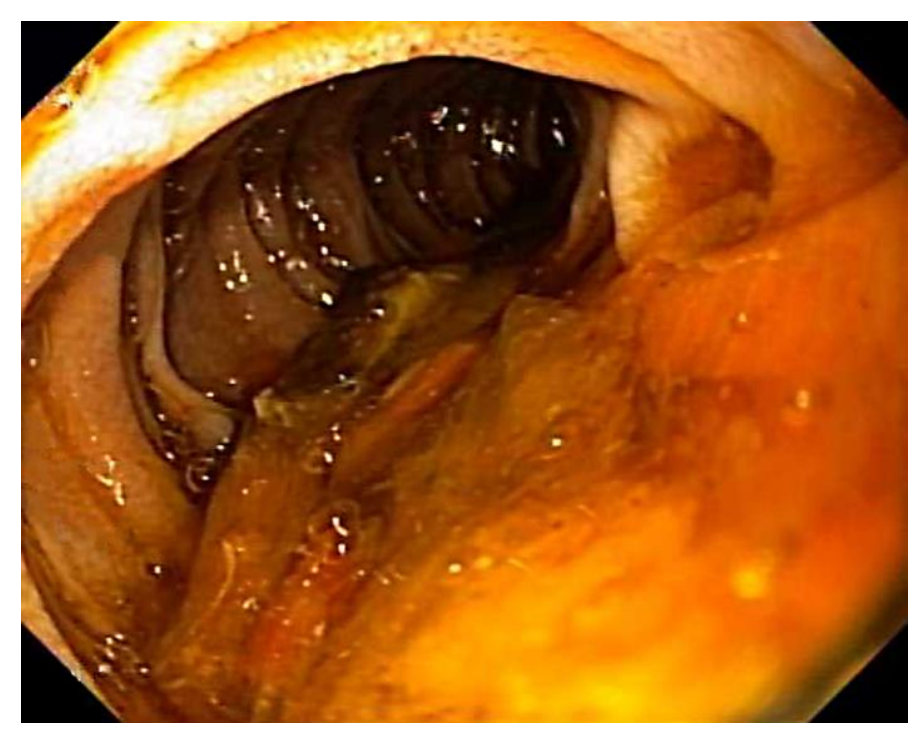

Fig. 1. Endoscopic appearance of the descending duodenum in a 74-year-old female showing retained, partially digested food in a small part of the descending duodenum, and no evident endoscopic abnormalities in the remaining $80 \%$ of the descending duodenum. Pathologic examination of endoscopic biopsies of normal appearing mucosa of the descending duodenum revealed MALToma. 

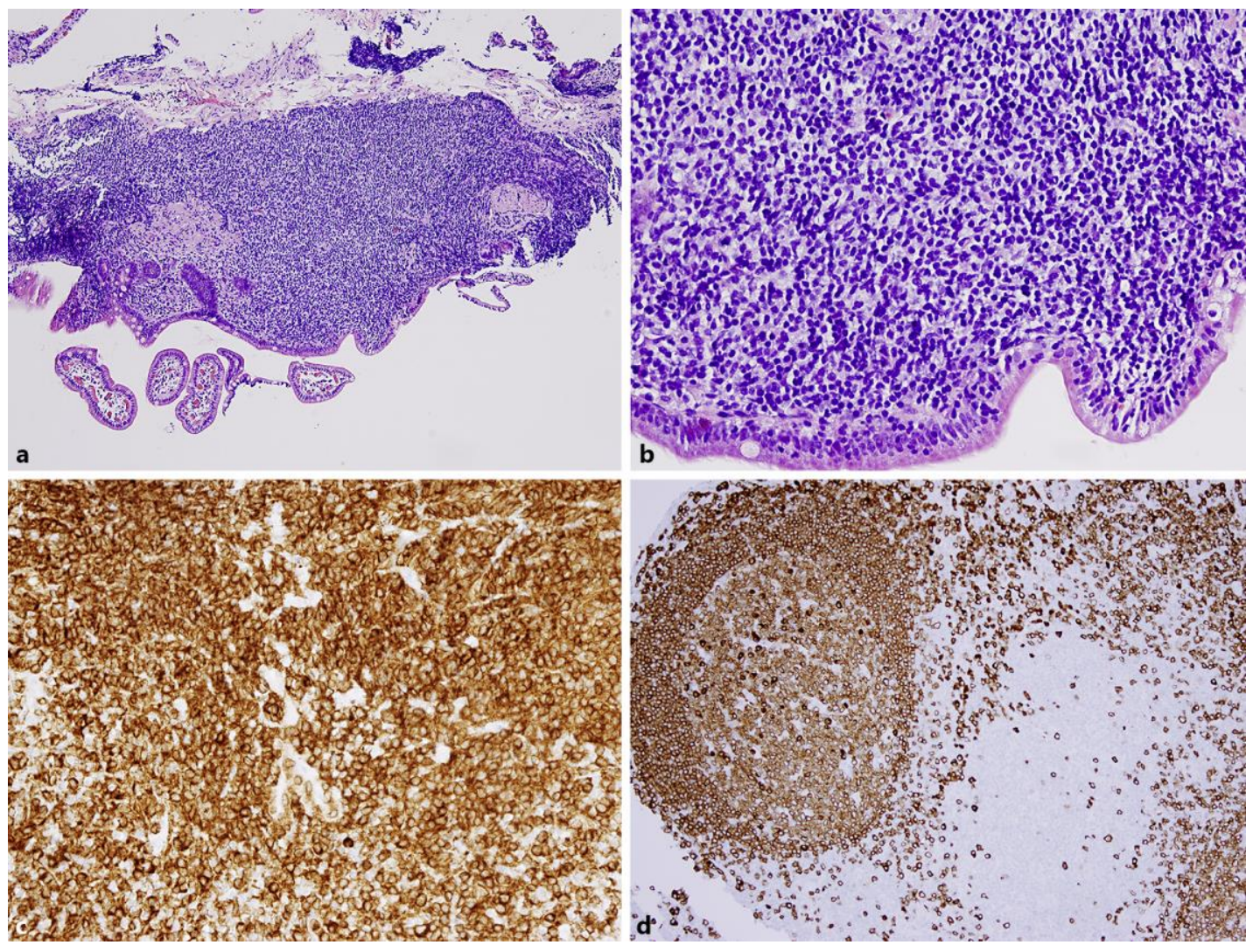

Fig. 2. Histopathologic examination of endoscopic biopsies of the descending duodenum in a 74-year-old woman with no evident endoscopic duodenal lesions. a Low-power photomicrograph from a duodenal biopsy showing a dense infiltrate of small mature lymphocytes extensively involving the submucosa, with otherwise unremarkable duodenal mucosa $(\mathrm{H} \& \mathrm{E}, \times 10)$. b High-power photomicrograph from a duodenal biopsy showing a monotonous proliferation of small mature lymphocytes, with some evident monocytoid differentiation $(H \& E, \times 40)$. c Immunohistochemistry for the B-cell marker CD79a shows strong positivity in most cells of the lymphocytic infiltrate, highly consistent with the diagnosis of a B-cell lymphoma $(\times 40)$. d Normal tonsil, used as an external control, demonstrates positive staining with CD79a on the left in a lymphoid follicle and absent staining with CD79a on the right in an adjacent area containing $\mathrm{T}$ cells. 